\title{
Extraction of Protodioscin from Tribulus terrestris-Optimisation of Kinetics and Modeling
}

\author{
EVGENI SIMEONOV ${ }^{1}$, ZVEZDELINA YANEVA $^{2 *}$, CHAVDAR CHILEV ${ }^{1}$ \\ ${ }^{1}$ Department of Chemical Engineering, University of Chemical Technology and Metallurgy, 8 Kl. Ohridski, 1756 Sofia, \\ Bulgaria \\ ${ }^{2}$ Chemistry Unit, Department of Pharmacology, Animal Physiology and Physiological Chemistry, Trakia University, \\ Students Campus, 6000 Stara Zagora, Bulgaria
}

\begin{abstract}
The aim of the present study was to establish the optimal conditions for protodioscin extraction from Tribulus terrestris plant and to investigate the possibilities of mathematical modeling of the process and calculation of the diffusion coefficients essential for the industrial scale-up and management of the extraction process. The kinetics of protodioscin extraction from Tribulus terrestris was experimentally studied at varying the solvent type (70\% and $96 \%$ ethanol) and temperature $\left(20^{\circ} \mathrm{C}, 30^{\circ} \mathrm{C}, 40^{\circ} \mathrm{C}\right)$. The optimal process conditions for these parameters were determined. The experimental results were mathematically modelled. Numerical solutions of the propsed in the study empirical model with constant and variable effective diffusivity in the solid phase, Deff, were obtained. The empirical model was based on comparative analyses with the Regular regime model solutions. It was established that the experimental data complied satisfactorily with the the resulting numerical solutions.
\end{abstract}

Keywords: steroidal saponin, Tribulus terrestris, extraction, kinetics, semiempirical calculations

\section{Introduction}

T. terrestris is a well-patronized medicinal herb used individually as a single therapeutic agent, as a prime or subordinate component of many pharmaceutically active formulations and food supplements [1,2]. The plant is found in compact fields in Bulgaria, Southern Europe and Central Asia. The whole herbaceous part contains saponins (triline, dioscin, grascillin, protodioscin, methylprotribescine, kukubasoponin) [3], flavonoids (rutin, astragaline, quercetin, kempferol, israminetin), sterols (sitosterol, campsterol), tannins, fatty oils and potassium salts [4]. It is found that in Bulgaria the content of furostanol saponins in the plant is 4 to 5 times higher as compared to that in plants from regions in China and India (Table 1), which except for protodioscin contain also protogracillin. According to a number of studies, spirostanol saponins accumulate mainly in the fruits, while furostanol - in the leaves [5-7].

Table 1. Protodioscin contents in the aerial parts of Tribulus terrestris from different georgraphical regions [5-9]

\begin{tabular}{|c|c|c|c|}
\hline Plant parts & Leaves & Stems & Fruits \\
\hline Bulgaria & $10003.5 \mu \mathrm{g} \mathrm{g}^{-1}$ dry wt. & $\begin{array}{l}193.3 \mu \mathrm{g} \mathrm{g}^{-1} \text { dry } \\
\text { wt. }\end{array}$ & $549.9-597.5 \mu \mathrm{g} \mathrm{g}^{-1}$ dry wt. \\
\hline China & & \multicolumn{2}{|c|}{$0.063-0.089 \%($ mixed sample) } \\
\hline India & $14.0 \mu \mathrm{g} \mathrm{g}^{-1}$ dry wt. & $4.0 \mu \mathrm{g} \mathrm{g}^{-1}$ dry wt. & $\begin{array}{c}2.4-6.5 \mu \mathrm{g} \mathrm{g}^{-1} \text { dry wt. } \\
0.067-0.317 \%\end{array}$ \\
\hline Turkey & - & - & $170.3-652.9 \mu \mathrm{g} \mathrm{g}^{-1}$ dry wt. \\
\hline Vietnam & - & - & $13.0 \mu \mathrm{g} \mathrm{g}^{-1}$ dry wt. \\
\hline Macedonia & \multicolumn{3}{|c|}{$0.649-0.730 \%$ (mixed sample) } \\
\hline Hungary & \multicolumn{3}{|c|}{$3040 \mu \mathrm{g} \mathrm{g}^{-1}$ dry wt. (mixed sample) } \\
\hline
\end{tabular}

*email: z.yaneva@abv.bg; zvezdelina.yaneva@trakia-uni.bg 
Protodioscin is one of the most widely investigated furostanol saponins, which is believed to be metabolized in the human organism to dihydroepiandrosterone (DHEA) - the precursor of sex hormones. T. terrestris has been explored exhaustively for its phytochemical and pharmacological activities such as diuretic, aphrodisiac, antiurolithic, immunomodulatory, antihypertensive, antihyperlipidemic, antidiabetic, hepatoprotective, anticancer, anthelmintic, antibacterial [10], analgesic, and antiinflammatory $[2,11,12]$. A study revealed that the di-p-coumaroylquinic acid derivatives extracted from aerial parts of Tribulus terrestris L. possess potent antioxidant activity, thus they were considered as the major constituents contributing to the antioxidant effect of the plant [13].

A number of recent scientific publications focus on the development and application of different efficient analytical methods for the quantitative determination of protodioscin in plant extracts: UV/VIS spectrophotometry [13,14], NMR [13], HPLC-ELSD [5], HPLC-DAD [7], LC/ELSD/MS/MS [5,9], HPLC-UV [8,9,15], HPTLC [6], Focused Microwave-Assisted Extraction coupled with GC/MS (FMAE/GC/MS) [16].

The extraction process is dependent on a number of variables which can impact the extraction parameters and the yield. Therefore, a specific mathematical method, which can take into account the effect of every single variable on the overall process efficiency, is necessary $[7,18]$. Response surface methodology is a statistical approach, which has been widely established to improve the extraction process with a minimal input of experimental data. With its the help the influence of various conditions on the extraction procedure can be simulated, both individually and through their cumulative interactions, thereby giving dry lab values for optimization of wet lab procedures $[18,19]$. One of the commonly used empirical models was the Peleg's one for the description of moisture sorption curve which could be adopted during extraction processes [20-22]. A number of factors such as solvent composition, extraction time, solid-to-liquid ratio, $p \mathrm{H}$, temperature, and particle size, might significantly influence the solid-liquid extraction processes [23]. The model trait is that it has only one adaptation parameter - the diffusion coefficient of the solute in the plant material, which depends on the solvent and plant material properties. Satisfactory agreement between the model results and the experimental data of the extraction of hydrophobic diterpene acids from sage leaves and hydrophilic flavonoids from common knotgrass herb was established [14].

The solid-liquid extraction of biologically-active substances from raw plant materials is almost ever limited by the mass transfer resistance inside the solid phase pores. The major factors that influence the rate of the diffusion process are quantitively expressed by the effective diffusivity and are represented in a concealed way by the experimental kinetics curve [24-26]. The Film theory model is able to describe the microwave-assisted extraction kinetics of flavonoid compounds from cocoa leaves under the effects of various operating parameters. Higher microwave heating power enhanced diffusivity, while greater solvent quantity to the feed ratio ensured lower mass transfer resistance and lead to improved equilibrium yield [27]. The combination of the experimental and process analytical data is used for the calculation of $D_{\text {eff }}$ using the methods of Standard function and Regular regime [28]. Recently, empirical models are widely preferred; however thermodynamics explanations have scarcely been presented. The base of its creation is the numerical analysis of the experimental data, their accurate description and simultaneous modelling of all studied extraction process parameters.

The aim of the present study was to establish the optimal conditions for protodioscin extraction from Tribulus terrestris plant and to investigate the possibilities of mathematical modeling of the process and calculation of the diffusion coefficients, essential for the industrial scale-up and management of the extraction process.

\section{Materials and methods}

\subsection{Materials and reagents}

Tribulus terrestris was collected from compact deposits in Southern Bulgaria in 2017. The entire aboveground part (Herba) was used in the present study. Prior to extraction the plant material was dried in a thin-layer in an oven at temperature within the range $\mathrm{T}=35-40^{\circ} \mathrm{C}$. The physicochemical properties 
of the raw plant material are presented in Table 2.

Table 2. Physicochemical characteristics of

Trubulus terrestris raw material

\begin{tabular}{|l|l|}
\hline Colour & yellow-brown \\
\hline Taste & bitter \\
\hline Odour & specific \\
\hline Moisture content, $\%$ & $\leq 6$ \\
\hline pH (aueous solution) & $3.0-5.5$ \\
\hline Heavy metals content, $\%$ & $\leq 0.001$ \\
\hline
\end{tabular}

The standard pure substance protodioscin (P) (C51H84O22, CAS 55056-80-9, > 98\%) was purchased from ChromaDex, USA. Acetonitrile (HPLC, 99.8\%) and ethanol (HPLC, > 99.8\%) were supplied by Sigma Aldrich.

\subsection{Extraction design and conditions}

Kinetics experiments of periodic extraction of Tribulus terrestris in a batch reactor were conducted. A number of experimental series were carried out at: solid/liquid ratio $\xi=0.02 \mathrm{~m}^{3} \mathrm{~kg}^{-1}$, temperature: $20^{\circ} \mathrm{C}, 30^{\circ} \mathrm{C}, 40^{\circ} \mathrm{C}$ and solvent concentrations: $70 \%$ and $96 \%$ ethanol. The agitation rate was $\mathrm{n}=5 \mathrm{~s}^{-1}$, at which the process is limited by internal diffusion (the external diffusion resistance is eliminated).

\subsection{HPLC method for protodioscin analysis}

Saponins are difficult to be isolated because of the accompanying organic and inorganic substances. In the present work, an HPLC method with ELSD (electronic light scattering) detector and protodioscin as a standard substance was applied. The chemical structure of the organic compound is presented in Figure 1.

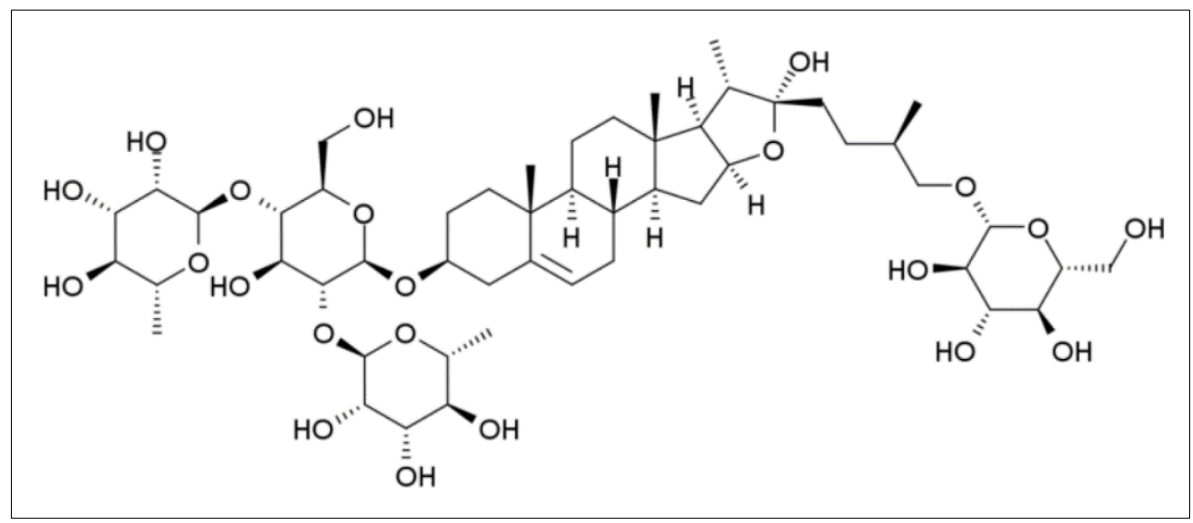

Figure 1. Protodioscin chemical structure

Agilent 1100 HPLC system comprising of a Supelco C18 (5 $\mu \mathrm{M}, 4.6$ x $150 \mathrm{~mm})$ column was used. The tested mobile phase consisted of a mixture of $\mathrm{ACN} / \mathrm{H}_{2} \mathrm{O}$. The samples were monitored at wavelength $\lambda 200 \mathrm{~nm}$ and temperature $\mathrm{T} 40^{\circ} \mathrm{C}$ [29]. The calibration curve (Figure 2A) was obtained on the basis of the analyzed standard protodioscin ethanol solutions with various initial concentrations. The area of the chromatographic peaks (Figure 2B) was logarithmized due to the specificity and the requirements of the detector used. The statistical significance of the experimental results was evaluated by the value of the least square deviation $\mathrm{R}^{2}$. 
A.
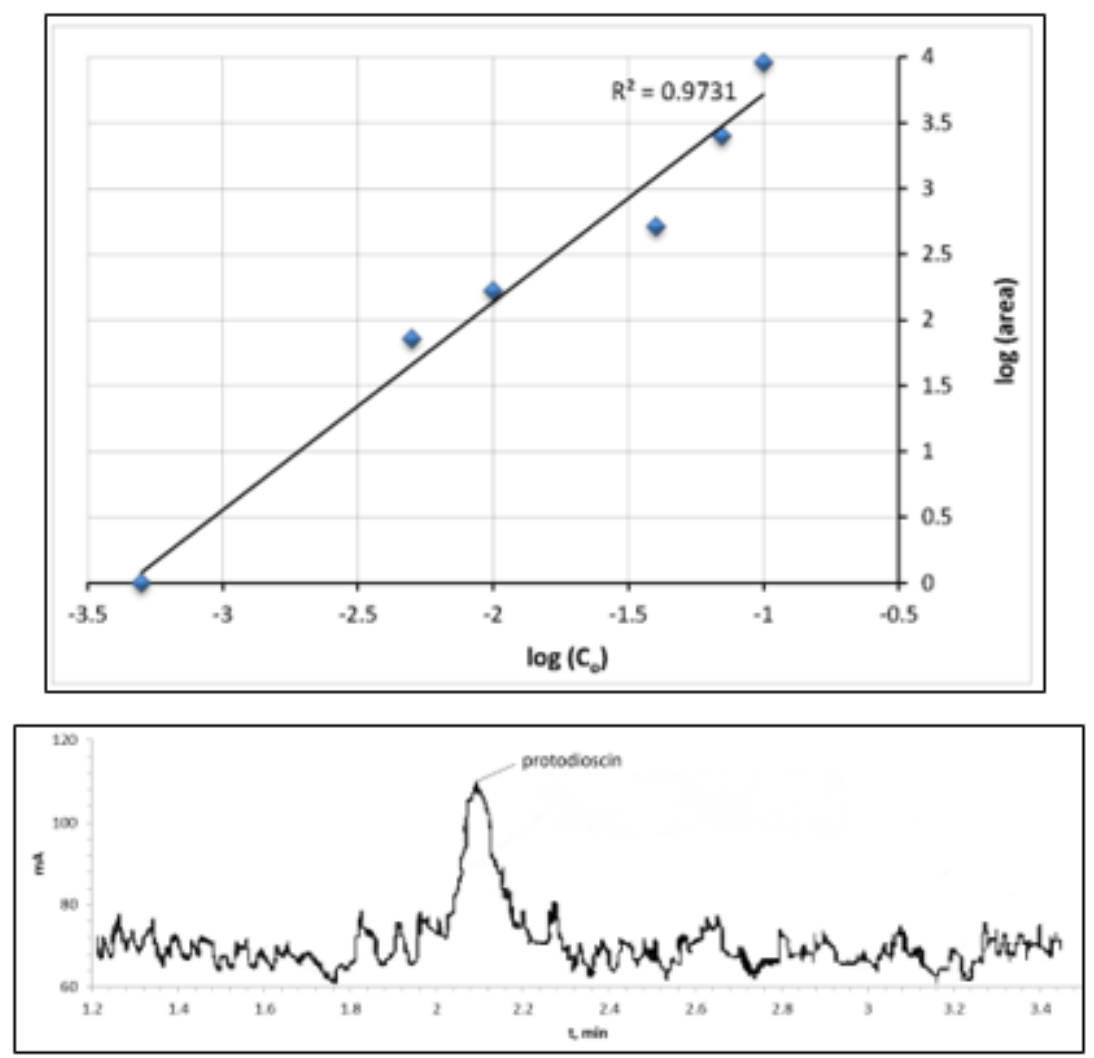

B.

Figure 2. A. Calibration curve, B. HPLC-ELSD spectrum of protodioscin analytical

\subsection{Extraction Modelling}

The calculation of $D_{\text {eff }}$ by non-stationary mass transfer was accomplished by two mathematical concepts - the Regular regime and Standard function models, which were applied in the comparative estimation of the compliance between the analytical/numerical data for solid phase for the three "classical" shapes and the experimental results (Table 3 ).

The methods applied are based on the analysis of the kinetics behavior of the studied system during the process of periodical solid-liquid extraction. 
Table 3 Modelling methods of protodioscin kinetics extraction

\begin{tabular}{|c|c|c|c|}
\hline Method & Model equations, boundary conditions & Parameters & Ref. \\
\hline \begin{tabular}{|l|} 
Kinetics \\
study and \\
diffusion \\
coefficients
\end{tabular} & $\begin{array}{l}\text { Diffusion model: } \\
\frac{\partial C_{2}(x, \tau)}{\partial \tau}=D_{\epsilon f f}\left[\frac{\partial^{2} C_{2}}{\partial X^{2}}+\frac{t}{X} \frac{\partial C_{2}}{\partial X}\right] \\
C_{2}=f(\tau) \text { for the boundary case: } B i \rightarrow \infty ; \beta \rightarrow 0 \\
B i=k \cdot R D_{s f}\end{array}$ & $\begin{array}{l}C_{2} \text { - the concentration in the solid phase; } \\
B i \text { - } B \text { iot number; } \\
k \text { - external mass transfer coefficient, } \mathrm{m} \cdot \mathrm{s}^{-1}\end{array}$ & [28] \\
\hline $\begin{array}{l}\text { Standard } \\
\text { function } \\
\text { method }\end{array}$ & 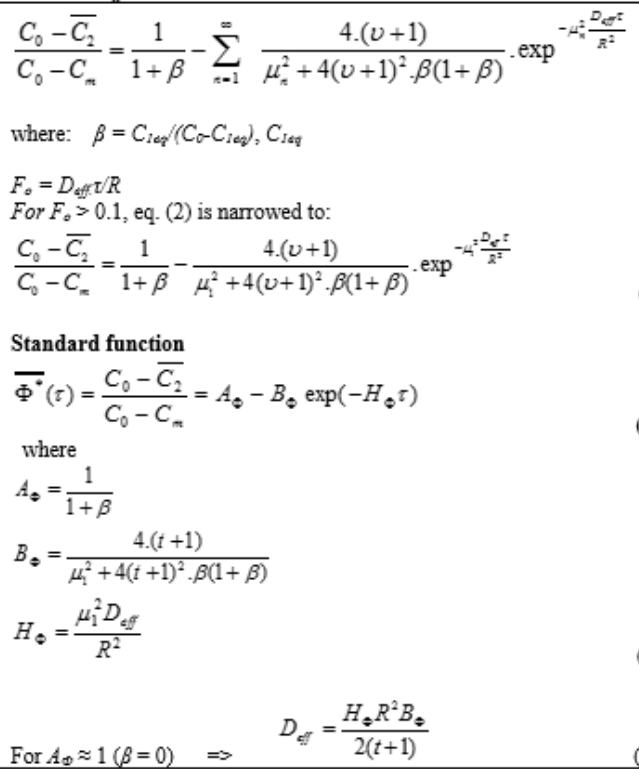 & 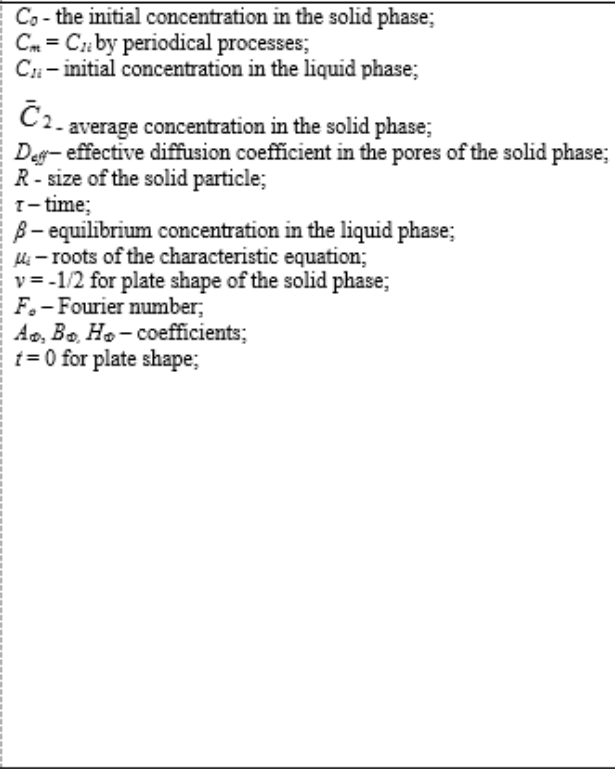 & {$[30,31]$} \\
\hline $\begin{array}{l}\text { Regular } \\
\text { regime }\end{array}$ & $\begin{array}{l}\text { - at the beginning of the regime } D_{e f f}=\text { const } \\
\text { for plate shape of the solid particles at } \tau=0,\end{array}$ & $\begin{array}{l}C_{I}-\text { concentration in the liquid phase; } \\
C_{l i}-\text { initial concentration in the liquid phase. }\end{array}$ & {$[24,30]$.} \\
\hline method & 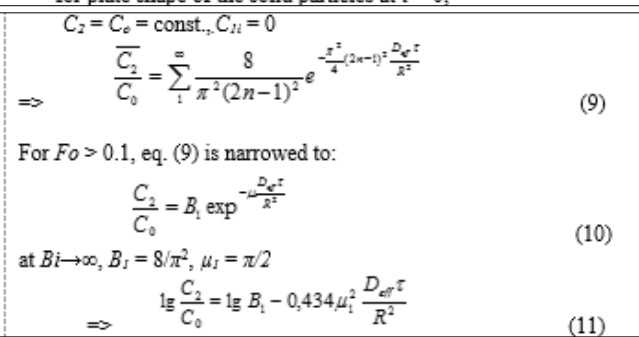 & & \\
\hline
\end{tabular}

\section{Results and discussions}

The modeling of the experimental results was performed using the MatLAB 7.0 software environment. Appropriate functions for solving the mathematical model with constant and variable effective diffusion coefficient in the solid phase were developed.

\subsection{Determination of $D_{\text {eff }}$}

The values of the constant effective diffusion coefficient, obtained by the Standard function method, at various working conditions are presented in Table 4.

Table 4. Values of $D_{\text {eff }}$ by the Standard function method

\begin{tabular}{|c|c|c|c|}
\hline $\begin{array}{c}D_{\text {eff }} \times 10^{8} / \mathrm{m}^{2} \mathrm{~s}^{-1} \\
\mathrm{~T}=20^{\circ} \mathrm{C} ; 70 \% \mathrm{EtOH}\end{array}$ & $\begin{array}{c}D_{\text {eff }} \times 10^{8} / \mathrm{m}^{2} \mathrm{~s}^{-1} \\
\mathrm{~T}=30^{\circ} \mathrm{C} ; 70 \% \mathrm{EtOH}\end{array}$ & $\begin{array}{c}D_{\text {eff }} \times 10^{8} / \mathrm{m}^{2} \mathrm{~s}^{-1} \\
\mathrm{~T}=40^{\circ} \mathrm{C} ; 70 \% \mathrm{EtOH}\end{array}$ & $\begin{array}{c}D_{\text {eff, }} \mathrm{X} 10^{8} / \mathrm{m}^{2} \mathrm{~s}^{-1} \\
\mathrm{~T}=30^{\circ} \mathrm{C} ; 96 \% \mathrm{EtOH}\end{array}$ \\
\hline 0.1093 & 0.0939 & 0.1136 & 0.0248 \\
\hline
\end{tabular}

The Regular regime method is predicated on a comparison between the experimental results obtained in the case of non-constant mass transfer from the solid into the liquid phase with the analytical solutions data obtained under identical mass transfer conditions. The computed $D_{\text {eff }}$ values are presented in Table 
5.

Table 5. $D_{\text {eff }}$ values by the Regular regime method

\begin{tabular}{|c|c|c|c|c|}
\hline$\tau / \mathrm{s}$ & $\begin{array}{c}D_{\text {eff }} \times 10^{8} / \mathrm{m}^{2} \mathrm{~s}^{-1} \\
T=20^{\circ} \mathrm{C} ; 70 \% \mathrm{EtOH}\end{array}$ & $\begin{array}{c}D_{\text {eff }} \times 10^{8} / \mathrm{m}^{2} \mathrm{~s}^{-1} \\
T=30^{\circ} \mathrm{C} ; 70 \% \text { EtOH }\end{array}$ & $\begin{array}{c}D_{\text {eff }} \times 10^{8} / \mathrm{m}^{2} \mathrm{~s}^{-1} \\
T=40^{\circ} \mathrm{C} ; 70 \% \mathrm{EtOH}\end{array}$ & $\begin{array}{c}D_{\text {eff, }} \mathrm{x} 10^{8} / \mathrm{m}^{2} \mathrm{~s}^{-1} \\
T=30^{\circ} \mathrm{C} ; 96 \% \mathrm{EtOH}\end{array}$ \\
\hline 600 & 0.2578 & 0.2594 & 0.2769 & 0.2448 \\
\hline 900 & 0.1763 & 0.1770 & 0.1875 & 0.1637 \\
\hline 1200 & 0.1377 & 0.1403 & 0.1421 & 0.1242 \\
\hline 1800 & 0.0943 & 0.0968 & 0.0966 & 0.0839 \\
\hline 3600 & 0.0475 & 0.0506 & 0.0541 & 0.0425 \\
\hline 7200 & 0.0239 & 0.0256 & 0.0273 & 0.0216 \\
\hline 10800 & 0.0170 & - & 0.0183 & 0.0148 \\
\hline 14400 & 0.0129 & 0.0139 & - & 0.0113 \\
\hline
\end{tabular}

A comparison between the $D_{\text {eff }}$ values obtained by both methods for the three working temperatures is graphically presented in Figure 3.

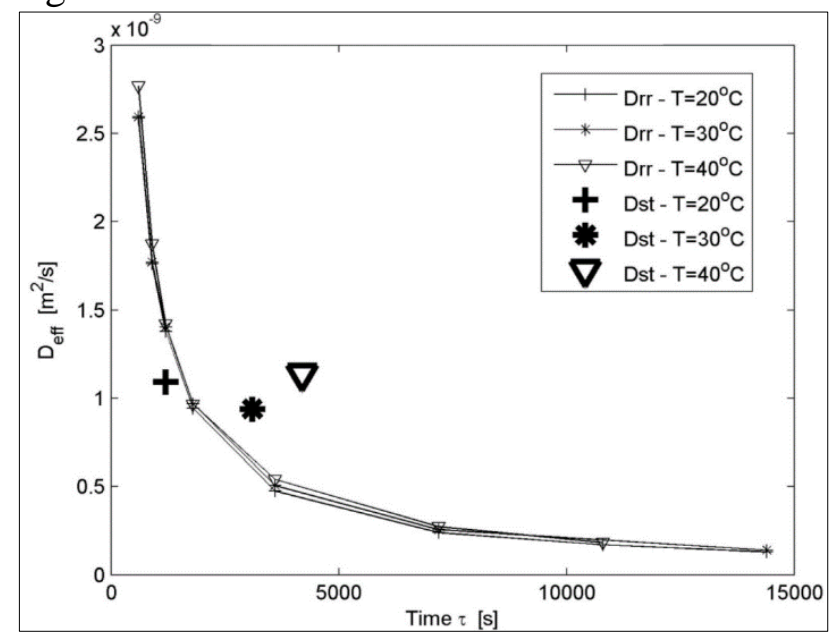

Figure 3. Values of the calculated by the Standard Function and Regular regime method

Figure 3 shows that the values obtained by the two methods are of the same order. In addition, the values obtained by the Standard function method can be considered as an average of these obtained by the Regular mode method. This is an indication of the accuracy of the obtained results.

\subsection{Approximation of $D_{\text {eff }}$}

The numerical solutions of the model are obtained by discretization of the partial differential equation (1) and the boundary conditions. If the Standard function method is used ( $D_{\text {eff }}=$ const.), the $D_{\text {eff }}$ value is applied directly to the model numeric scheme. If the Regular regime method, $D_{\text {eff }} \neq$ const., is applied, then the number of the variable $D_{\text {eff }}$ values has to correspond to the number of the sampling points for discretization of the defined numerical network. The calculated $D_{\text {eff }}$ values presented in Table 5 are obtained on the basis of the experimental data. Thus, their number corresponds to the number of the experimental points, but not to the number of the discretized points of the numerical network. The latter defines the necessity of approximation of the data from Table 5 with an appropriate function, which could later be applied in the numerical scheme of the model. The application of the selected approximation function allows the calculation of the value of $D_{\text {eff }}$ for any point in the numerical network. Thus, the values of the effective diffusivity, obtained by the Regular regime model (Table 5), have to be approximated. Therefore, these values are hereinafter referred to as "experimental", on the basis of which non-linear regression was performed. As the effective diffusion coefficient depends on the 
extraction kinetics, multidimensional nonlinear diffusion of the data is required. An empirical model for calculating the effective diffusion coefficient for the extraction of biologically-active components from plant raw materials - eq. (12), is presented in the study of [25].

$$
D_{\text {eff }}=\left[a(\xi c)^{2}+b \xi c+d\right] T^{f} \exp (-m \tau)+n \exp (-p \tau)
$$

Eq. (12) is a seven-parameter model and its parameters $a, b, d, f, m, n$ and $p$ can be calculated via multidimensional nonlinear regression of the $D_{\text {eff }}$ values obtained by the Regular regime method for all process conditions.

In the present study all experiments were carried out at a steady solid/liquid ratio $\xi=0.02 \mathrm{~kg} / \mathrm{m}^{3}$. Thus, the effect of $\xi$ was excluded and eq. (12) was reduced to a three-dimensional model, considering the influence of the concentration of the two-component mixed solvent, temperature and time on the $D_{\text {eff }}$ values change. In this respect, eq. (12) was transformed as follows:

$$
D_{\text {eff }}=\left(a c^{2}+b c+d\right) T^{f} \exp (-m \tau)+n \exp (-p \tau)
$$

Equation (13) is also a seven-parameter one, but it does not include the modification of the solid/liquid ratio. To determine the parameters of this equation, multidimensional non-linear regression of the data for $D_{\text {eff }}$ in Table 5 has to be conducted. The regression analyses were performed by the inlinfit function of the Matlab program environment. The results obtained are presented in Table 6.

Table 6. Values of the parameters in eq. (13)

\begin{tabular}{|c|c|}
\hline Model parameter & Value \\
\hline$a$ & $1.015 \times 10^{-8}$ \\
\hline$b$ & $-1.867 \times 10^{-8}$ \\
\hline$d$ & $1.141 \times 10^{-8}$ \\
\hline$f$ & 0.1391 \\
\hline$m$ & $-1.176 \times 10^{-3}$ \\
\hline$n$ & $9.723 \times 10^{-10}$ \\
\hline$p$ & $-1.164 \times 10^{-4}$ \\
\hline
\end{tabular}

The values of $D_{\text {eff }}$ at various temperatures (Table 5) and their approximation by eq. (13) are graphically presented in Figure 4.

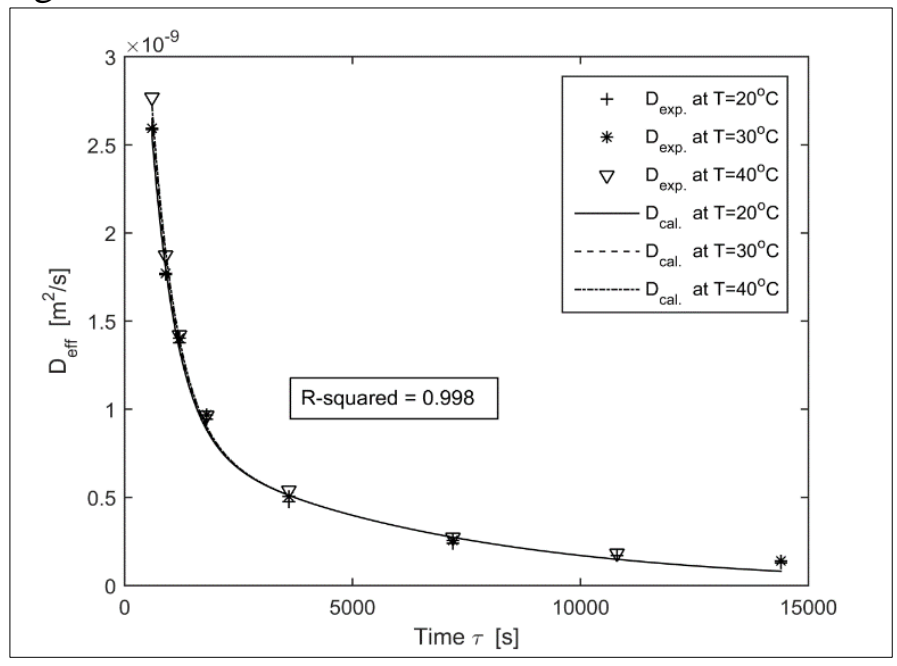

Figure 4. Experimental and approximated values of $D_{\text {eff }}$ at different temperatures 
The comparative analyses of the model and experimental curves in Figure 4 established significant compliance between the experimental results and model data, which is an indication that eq. (13) is suitable for approximation of the results obtained by the Regular regime method.

3.3. Numerical solutions of the mathematical model

The numerical solutions and experimental points of protodioscin extraction at $30^{\circ} \mathrm{C}$ with different solvents are presented in Figure 5 as plots of $c_{1} v s$. time, $\tau$.

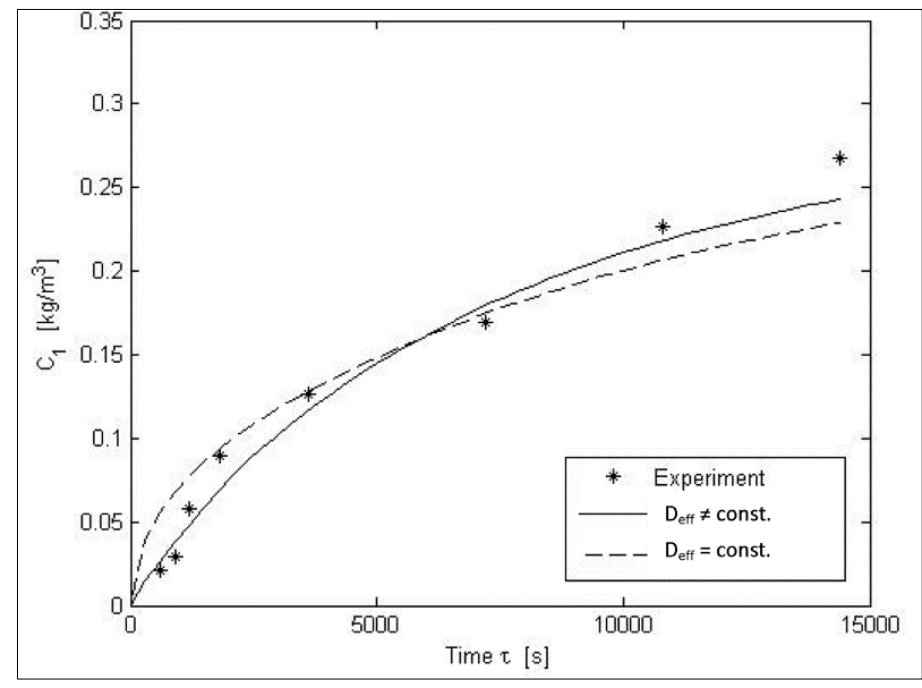

Figure 5. Experimental and model results for constant and non-constant effective diffusivity $\left(\mathrm{T}=30^{\circ} \mathrm{C}\right)$

In this case, the experimental results were modeled by $D_{\text {eff }}=$ const. (defined by the Standard function method), $D_{\text {eff }} \neq$ const. (determined by the Regular regime model) and $D_{\text {eff }}$ values approximated by eq. (13). Evidently, the deviations between the model results obtained by both methods are insignificant. The latter is due to the fact that $D_{\text {eff }}$ values during the extraction process change in very narrow ranges from approximately $0.25 \times 10^{-8} \mathrm{~m}^{2} / \mathrm{s}$ to $0.013 \times 10^{-8} \mathrm{~m}^{2} / \mathrm{s}$ (Table 5). Based on these data, it could be concluded that the results obtained at $D_{\text {eff }} \neq$ const. described more precisely the experimental points. Analogous results were obtained for the mathematical modeling of the experimental series at all the other cited working conditions. Therefore, the concept of applying variable effective diffusivity for the performance of the numerical solution at the studied operating conditions was adopted. Figure 6 presents the experimental points and model data for protodisocin extraction with $70 \%$ and $96 \% \mathrm{EtOH}$ solutions as solvents.

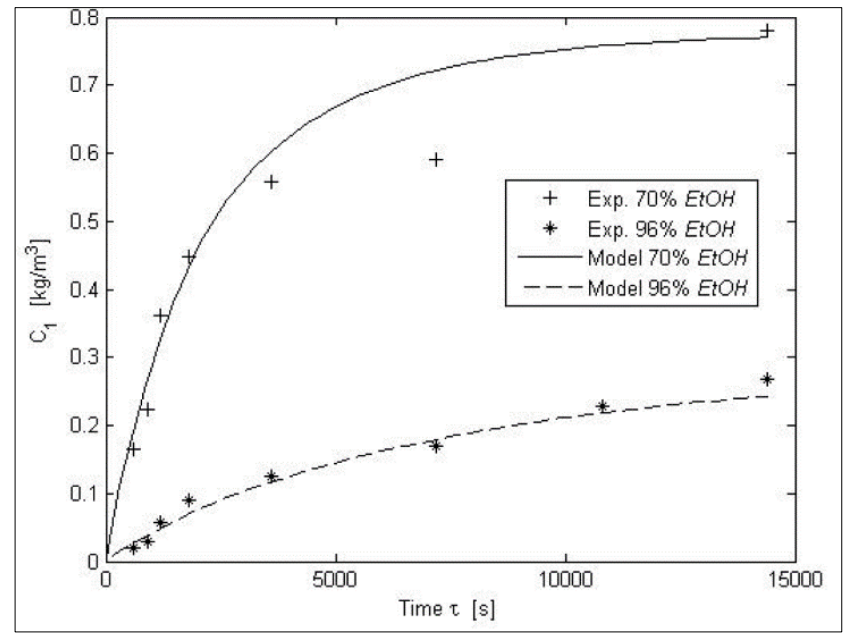

Figure 6. Experimental and model results for protodioscin extraction with different solvents $\left(\mathrm{T}=30^{\circ} \mathrm{C}\right)$ 
Evidently, in both cases, satisfactory conformity between the experimental results and model data was established. However, the application of $70 \% \mathrm{EtOH}$ as a solvent was more favourable due to the achievement of significantly higher yield of the target component - protodioscin, .

The effect of temperature on the kinetics behavior of the studied system with $70 \% \mathrm{EtOH}$ is presented in Figure 7.

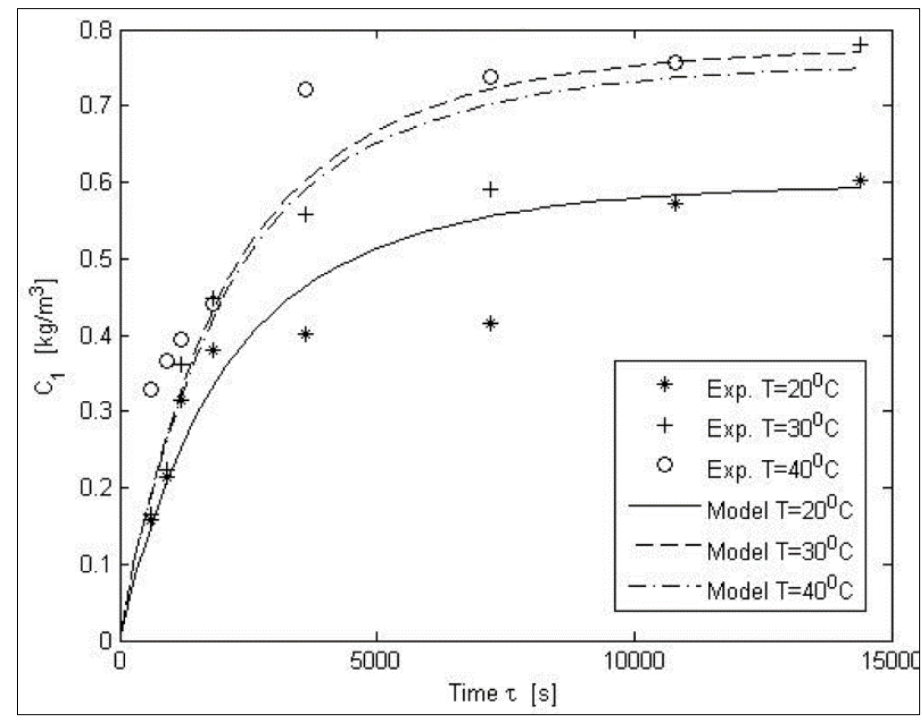

Figure 7. Effect of temperature on the experimental and model data of protodioscin extraction with $70 \% \mathrm{EtOH}$

Based on these results, a direct relationship between the temperature increase and the quantity of the extracted component was established. The deviations between the model curves for the experimental series at $30^{\circ} \mathrm{C}$ and $40^{\circ} \mathrm{C}$ in the final phase were insignificant. Consequently, at the end of the separation process the amounts of protodioscin extracted in both cases were approximately equal.

\section{Conclusions}

The kinetics of protodioscine extraction from Tribulus terrestris with $70 \%$ and $96 \% \mathrm{EtOH}$ as solvent at $\mathrm{T} 20^{\circ} \mathrm{C}, 30^{\circ} \mathrm{C}$ and $40^{\circ} \mathrm{C}$ was studied. The extraction of the target compound with $70 \% \mathrm{EtOH}$ was more favourable due to the significantly higher yield achieved. Due to the molecular protodioscine structure, the presence of water in the extractant significantly increased the rate of extraction. A direct relationship between the temperature increase and the efficiency of the target compound extraction, at identical other operating conditions, was determined. The latter is explained by mass transfer intensification at higher temperature due to increased solubility of the target components in the solvent. On the other hand, the free flow of molecules in the liquid phase also increased, which facilitates the interaction between the solvent and the solid phase. However, extraction at high temperature is not always possible. Most valuable natural components are unstable at temperatures above $40-50^{\circ} \mathrm{C}$, as they lose their bioactive properties. In addition, the increase in the process temperature is always associated with the use of extra energy, which makes production more expensive. The obtained experimental results show that the differences between the equilibrium concentrations of protodioscin at $\mathrm{T} 30$ and $40^{\circ} \mathrm{C}$ were very low. Consequently, at both temperatures at the end of the process, the amount of protodioscin extracted was almost the same. In this respect, extraction at $30^{\circ} \mathrm{C}$ was proved as economically more advantageous.

The results obtained and the conclusions derived are indicative that the proposed empirical equation (2) is appropriate for the approximation of the experimental results of protodioscin extraction from Tribulus terrestris. 
Acknowledgments: This work was supported by the Science \& Research Programme of the UCTM Sofia (Project 11 654) and the Bulgarian Ministry of Education and Science under the National Research Programme "Healthy Foods for a Strong Bio-Economy and Quality of Life" approved by DCM \# 577/17.08.2018".

\section{References}

1.ZHELEVA-DIMITROVA, D., OBRESHKOVA, D., NEDIALKOV, P., Antioxidant activity of Tribulus terrestris - a natural product in infertility therapy, Int J Pharm Pharm Sci, 4(4), 2012, 508-511. 2.CHHATRE, S., NESARI, T., SOMANI, G., KANCHAN, D., SATHAYE, S., Phytopharmacological overview of Tribulus terrestris, Phcog Rev, 8, 2014, 45-51.

3.HAMED, AL., JANDA, B., MAHALEL, U.A., STOCHMAL, A., OLESZEK, W., Profiles of steroidal saponins from the aerial parts of Tribulus pentandrus, $T$. megistopterus subsp. pterocarpus and $T$. parvispinus by LC-ESI-MS/MS, Phytochemical Analysis, 23(6), 2022, 613-621.

4.MITRA, N., MOHAMMAD-MEHDI, D., REZA, Z. M., Tribulus terrestris L. (Zygophyllaceae) flavonoid compounds, International Journal of Modern Botany, 2(3), 2012, 35-39.

5.DINCHEV, D., JANDA, B., EVSTATIEVA, L., OLESZEK, W., ASLANI, M.R., KOSTOVA, I., Distribution of steroidal saponins in Tribulus terrestris from different geographical regions, Phytochemistry, 69, 2008, 176-186.

6.RAWAT, A.K.S., SRIVASTAVA, A., TIWARI, S.S., SRIVASTAVA, S., Quantification of protodioscin and prototribestin in fruits of Tribulus terrestris L. collected from different phytogeorgraphical zones of India, Journal of Liquid Chromatography \& Related Technologies, 36(13), 2013, 1810-1821.

7.SHISHOVSKA, M., SARAFINOVSKA, Z.A., MEMETI, Sh., A simple method for determination of protodioscin in Tribulus terrestris L. and pharmaceuticals by High-Performance Liquid Chromatography using Diode-Array Detection, Journal of Chemical Engineering Research Updates, 2, 2015, 12 21.

8.IVANOVA, I., LAZAROVA, P., MECHKAROVA, P., TCHORBANOV, B., HPLC method for screening of steroidal saponins and rutin as biologically active compounds in Tribulus terrestris L, Biotechnol. \& Biotechnol. Eq., 24, 2010, 129-133.

9.KOSTOVA, D., DINCHEV, D., Saponins in Tribulus terrestris - chemistry and bioactivity, Phytochemistry Reviews, 4, 2005, 111-137.

10.KIRAN, B., LALITHA, V., RAVEESHA, K.A., In vitro evaluation of aqueous and solvent extract of Tribulus terrestris L. leaf against human bacteria, Int J Pharm Tech Res, 3, 2011, 1897-1903.

11.OH, J.S., BAIK, S.H., AHN, E.K., JEONG, W., HONG, S.S., Anti-inflammatory activity of Tribulus terrestris in RAW264.7 cells, J Immunol, 88, 2012, 54.2.

12.RAOOFI, A., KHAZAEI, M., GHANBARI, A., Protective effect of hydroalcoholic extract of Tribulus terrestris on cisplatin induced renal tissue damage in male mice, Int J Prev Med, 6, 2015, 1117.

13.HAMMODA, H.M., GHAZY, N.M., HARRAZ, F.M., RADWAN, M.M., ELSOHLY, M.A., ABDALLAH, I.I., Chemical constituents from Tribulus terrestris and screening of their antioxidant activity, Phytochemistry, 92, 2013, 153-159.

14.SALAMATIN, A.A., KHAZIEV, R.SH., MAKAROVA, A.S., IVANOVA, S.A., Kinetics of Bioactive Compounds Extraction from Plant Material Using Boiling Solvent, Teoreticheskie Osnovy Khimicheskoi Tekhnologii (Theoretical Foundations of Chemical Engineering), 49(2), 2015, 206-213. 15.LOZANO, M.C., MARTINEZ, N.M., DIAZ, G.J., Content of the saponin protodioscin in Brachiaria spp. from the Eastern Plains of Colombia Toxins, 9, 2017, 220-232.

16.LI, T., ZHANG, Z., ZHANG, L., HUANG, X., LIN, J., CHEN, G., An improved facile method for extraction and determination of steroidal saponins in Tribulus terrestris by focused microwave-assisted extraction coupled with GC-MS, J Sep Sci., 32(23-24), 2009, 4167-4175. 
17.VELIC, D., JOKIC, S., BUCIC-KOJIC, A., BILIC, M., PLANINIC, M., VELIC, N., KRESOJA, D., Mathematical modeling of total flavonoid compounds extraction from conventionally grown soybeans, Proceedings. $46^{\text {th }}$ Croatian and $6^{\text {th }}$ International Symposium on Agriculture. Opatija. Croatia, 2011, 690694.

18.KAUSHIK, J., TANDON, S., GUPTA, V., NAYYAR, J., SINGLA, S.K., TANDON, C., Response surface methodology based extraction of Tribulus terrestris leads to an upsurge of antilithiatic potential by inhibition of calcium oxalate crystallization processes, PLOS ONE, 12(8),2017, e0183218.

19.CRISTINA, P., DANIEL, G., NEIVA, D., ROSSO, D., Extraction of anthocyanins and polyphenols from black rice (Oryza sativa L.) by modeling and assessing their reversibility and stability, Food Chemistry, 191, 2016, 12-20.

20.PELEG, M., An empirical model for the description of moisture sorption curves, J. Food Sci., 53, 1988, 1216-1217.

21.JOKIĆ, S., VELIĆ, D., BILIĆ, M., BUCIĆ-KOJIĆ, A., PLAINIĆ, M., TOMAS, S., Modelling of the process of solid-liquid extraction of total polyphenols from soybeans, Czech J Food Sci., 28, 2010, 206-212.

22.KITANOVIĆ, S., MILENOVIĆ, D., VELJKOVIĆ, V.B., Empirical kinetic models for the resinoid extraction from aerial parts of St. John's wort (Hypericum perforatum L.), Biochem Eng J., 41, 2008, 111.

23.FAN, R., YUAN, F., WANG, N., GAO, Y., Extraction and analysis of antioxidant compounds from the residues of Asparagus officinalis, J Food Sci Technol., 52(5), 2015, 2690-2700.

24.SIMEONOV, E., YANEVA, Z., CHILEV, Ch., Kinetics of green solid-liquid extraction of useful compounds from plant materials: kinetics coefficients and modeling, Green Processing and Synthesis, 7(1), 2017, 68-73.

25.CHILEV, Ch., KOLEVA, V., SIMEONOV, E., A new empirical model for calculation the effective diffusion coefficient for solid-liquid extraction from plants, Ind. Eng. Chem. Res., 53, 2014, 6288-6296. 26.SIMEONOV, E., TSIBRANSKA, I., MINCHEV, A., Solid-liquid extraction from plants experimental kinetics and modelling, Chem. Eng. J., 73, 1999, 255-259.

27.CHAN, C.H., YUSOFF, R., NGOH, G.C., Assessment of scale-up parameters of microwave-assisted extraction via the extraction of flavonoids from cocoa leaves, Chem. Eng. Technol., 38(3), 2015, 489496.

28.SIMEONOV, E., CHILEV, Ch., Modeling and kinetics study of solid-liquid extraction from leaves of Nicotiana tabacum L., Journal of Chemical Technology and Metallurgy, 50(5), 2015, 597-600.

29.GANZERA, M., BEDIR, E., KHAN, I.A., Determination of steroidal saponins in Tribulus terrestris by reversed-phase high-performance liquid chromatography and evaporative light scattering detection, J Pharm Sci, 90(11), 2001, 1752-1758.

30.AXELROOD, G., LISJANSKI, W., Extraction (Solid-liquid systems), Chimia, St. Peterburg (1974), USSR, pp. 78-80.

31.A. MINCHEV, S. MINKOV, A model for determination of the effective diffusion coefficient by the Standard Function Technique, Journal of Applied Chemistry 57, 1984, 717-720.

$\overline{\text { Manuscript received: } 13.05 .2020}$ 